\title{
DECISION SUPPORT SYSTEM FOR CUSTOMERS DURING AVAILABILITY OF TRADE CREDIT FINANCING WITH DIFFERENT PRICING SITUATIONS
}

\author{
Ali Akbar Shaikh ${ }^{1}$, Subhash Chandra Das ${ }^{2}$, Asoke Kumar Bhunia ${ }^{1}$ and \\ BISWAJIT SARKAR ${ }^{3, *}$
}

\begin{abstract}
This study introduces an inventory system with a non-instantaneous deteriorating product with credit facility and variable demand depending on the selling price. Two different selling prices are considered in the deterioration and non-deterioration periods. Shortages are partially backlogged and dependent on the length of the customers' waiting time upto the arrival of fresh lot. Alternative trade-credit policy is applied herein, and several cases, sub-cases and situations are investigated. The corresponding optimization problems of different cases, sub-cases and situations are solved using an interval-oriented multi-section technique with the help of interval mathematics and interval order relations. A numerical example with three different credit periods is studied and solved to validate the said problem. Also, two different case studies are investigated. Then to investigate the effect of changes of several system parameters on the optimal policy, post optimality analyses are performed.
\end{abstract}

Mathematics Subject Classification. 90B05.

Received July 11, 2020. Accepted January 25, 2021.

\section{INTRODUCTION}

Every business organization is forced to maintain a large inventory of products to fulfill the demand of retailer and customer. However, maintaining the appropriate inventory is quite difficult without proper planning and strategies because the current business situation is highly competitive. In this connection, every organization is required proper planning to efficiently run their business. Every business organization generally opts for several kinds of strategies, including controlling product deterioration, maintaining the inventory to fulfill the retailers' demand and introducing different kinds of offer to attract retailer. In the next section, inventory related literature is discussed in details.

Keywords. Inventory, non-instantaneous deterioration, credit policy, partial backlogging.

1 Department of Mathematics, The University of Burdwan, Burdwan 713104, India.

2 Department of Mathematics, Chandrapur College, Chandapur, Burdwan 713145, India.

3 Department of Industrial Engineering, Yonsei University, 50 Yonsei-ro, Sinchon-dong, Seodaemun-gu, Seoul 03722, South Korea.

*Corresponding author: bsbiswajitsarkar@gmail.com 


\subsection{Literature review}

The deterioration effect of an item generally does not start instantly after the replenishment of product. It starts after a certain period of time. This was not considered when first inventory model was first developed (Harris-Wilson inventory model). However, in reality, most of the items continuously deteriorate with the passage of time due to several factors. Therefore, the deterioration effect cannot be discarded when studying inventory control problems. Ghare and Schrader [11] first considered this effect in formulating their inventory model. Emmons [10] then introduced Weibull (two parameter) distributions to demonstrate the deterioration rate of an item in the inventory analysis. Sarma [42] introduced an inventory model for a perishable item under a two-warehouse system. Meanwhile, Mandal and Phaujdar [30] proposed a deteriorating inventory model, where demand of the product was dependent on the stock. Pakkala and Achary [34] discussed an inventory problem with a deterioration effect under a two-storage facility. Wee [53] proposed a deteriorating inventory model under shortage. In addition, Benkherouf [3] discussed a two-warehouse system under the deterioration effect. Chang et al. [7] investigated an inventory problem with the deterioration effect under trade-credit policy. Papachristos and Skouri [36] introduced a quantity discount inventory model with deterioration. Balkhi and Benkherouf [2] proposed a stock-dependent demand related inventory model under deterioration. Hou [14] discussed a stock-dependent inventory problem for deteriorating items with inflation. Moreover, Dye et al. [9] introduced an inventory model for deteriorating item with a capacity constraint. Roy [38] investigated a time-varying holding cost-related deteriorating inventory model. Lee and Dye [20] proposed a stock-dependent demand related inventory model under deterioration. Mishra et al. [32] investigated a time-varying holding cost-related inventory problem along with shortages. In this connection, we may refer to the works of Jaggi et al. [15] and Shaikh et al. [45] among others.

Suppliers/retailers may offer several kinds of facilities to their customers due to globalization marketing policy. Trade-credit financing is one of the popular facility in the business world. Retailers are motivated to purchase more products for their business due to the availability of credit facilities for the procured quantity of the products. In this agreement, during the allowable time period for availability of trade-credit facility, a supplier does not charge any interest to his retailers. However, according to the terms and conditions, a supplier charges interest from his retailers if the retailers don't able to make payment within the stipulated time period. This type of offer is generally known as allowable trade credit financing or allowable delay-in-payments. This concept of delay in payments was first proposed by Haley and Higgins [13] in the area of inventory control. Goyal [12] then developed a credit policy approach in an inventory model. Aggarwal and Jaggi [1] modified Goyal's approach under the assumption of deterioration. Jamal et al. [19] modified Aggarwal and Jaggi's approach by introducing backlogged shortage [1], after which a number of works was performed by several other researchers. Teng et al. [50] proposed an inventory model with a credit policy approach. Soni et al. [48] introduced a comprehensive study on credit policy on inventory. Liang and Zhou [21] introduced a credit policy inventory model in a two-warehouse system for deteriorating items. Maiti [29] proposed a credit-linked promotional demand on an inventory system. Kumar et al. [26] introduced an inventory model with a variable demand dependent on price considering the trade-credit facility. Sarkar et al. [39] studied a credit policy inventory problem with a finite replenishment rate. Similarly, Liao et al. [22] introduced another important factor of permissible delay in payment with the capacity constraint of the warehouse in an inventory system. Pal et al. [35] proposed a three-stage credit concept in their inventory model. Wu et al. [54] introduced a maximum life time-related inventory model with a two-level credit policy. Meanwhile, Shah and Cardenas-Barron [43], Jaggi et al. [16], and Tayal et al. [49] considered both trade-credits and preservation technology in their inventory models. Singh et al. [47] formulated a stockdependent demand related inventory model under the credit policy approach. Bhunia et al. [6] introduced a partially integrated production problem with a reliability factor and a price-dependent demand in an interval environment. They solved the corresponding optimization problem using the soft computing technique. Mashud et al. [31] studied a sustainable inventory model in two warehouse system under advance and trade credit facilities. Tiwari et al. [51] proposed a multi-item green production system under trade credit facility. Sarkar et al. [41] introduced multi trade credit facility in sustainable inventory management. Khanna et al. [24] studied a supply chain system where the credit facility is considered as customer based two level credit facilities. Kumar 
TABLE 1. Trade credit policy-related literature in the area of inventory control system.

\begin{tabular}{|c|c|c|c|c|}
\hline Author(s) & Demand rate & Shortage policy & $\begin{array}{l}\text { Level of } \\
\text { trade-credit } \\
\text { policy }\end{array}$ & Solution technique \\
\hline Bhunia et al. [5] & Fixed & $\begin{array}{l}\text { Partial } \\
\text { Backlogging }\end{array}$ & Single & Lingo software \\
\hline Khanra et al. [25] & Time dependent & $\begin{array}{l}\text { Complete } \\
\text { backlogging }\end{array}$ & Single & Not mentioned \\
\hline Chung et al. [8] & Constant & No & Two & Not mentioned \\
\hline Jaggi et al. [17] & Constant & No & No & Maple software \\
\hline Jaggi et al. [18] & Selling price dependent & No & Single & Not mentioned \\
\hline Sarkar et al. [40] & Constant & No & Two & Mathematica software \\
\hline Mohsen et al. [33] & Constant & $\begin{array}{l}\text { Complete } \\
\text { backlogging }\end{array}$ & Two & Not mentioned \\
\hline Pervin et al. [37] & Time dependent & No & Single & Newton-Raphson Method \\
\hline Kundu et al. [28] & Selling price dependent & No & $\mathrm{No}$ & PSO \\
\hline Shah et al. [44] & Quadratic demand & No & Single & Not mentioned \\
\hline $\begin{array}{l}\text { Udayakumar and } \\
\text { Geetha [52] }\end{array}$ & Constant & No & Single & Not mentioned \\
\hline This paper & $\begin{array}{l}\text { Selling price dependent } \\
\text { with different rates }\end{array}$ & $\begin{array}{l}\text { Partial } \\
\text { backlogging } \\
\text { (waiting time } \\
\text { dependent) }\end{array}$ & $\begin{array}{l}\text { Single (alter- } \\
\text { native } \\
\text { approach) }\end{array}$ & Multi-section technique \\
\hline
\end{tabular}

et al. [27] proposed a pricing, free replacement and warranty policies in inventory system for new launching product. Shin et al. [46] studied an effect of human errors in trade credit financing policy.

Apart from these, some recent works along with our proposed work are shown in a tabular form in Table 1.

An inventory model is formulated herein for not instantly starting deteriorating products by taking an alternative approach of the trade-credit policy and variable demand. Shortages are partially allowed with the variable rates dependent on customer's waiting time. Several situations are studied depending on the trade-credit policy, time for zero ending inventory, cycle length, and mode of payment. The interval-oriented multi-section optimization technique (IOMOT) [23] is applied to solve the optimization problems of these situations by using interval mathematics and interval order relations [4].

\section{Assumptions And notation}

The proposed model is developed under the following assumptions and notation.

\subsection{Assumptions}

(i) The demand rate $D(p)$ dependent on the selling price $(p)$ is given by

$$
D(p)= \begin{cases}D_{1}(p), & 0<x \leq x_{d} \\ D_{2}(p), & x>x_{d}\end{cases}
$$

where $D_{1}(p)=a-b p_{1}\left(a>b p_{1}\right), D_{2}(p)=a-b p_{2}\left(a>b p_{2}\right), p_{2}<p_{1}$ and $a \& b$ are positive constants.

(ii) Items start to deteriorate after a period of time $x_{d}$ and shortages are allowed with the backlogging rate dependent on the customer's waiting time upto the arrival of fresh lot. The mathematical form of the backlogging rate is given by $[1+\mu(X-x)]^{-1}, \mu>0$. 
(iii) If $X \geq T$, then the credit period is settled at $T$. After this time period, the retailer must pay interest with the rate $I_{p}$. Before this time period, the retailer can also earn interest with the rate $I_{e}$ where $I_{p} \geq I_{e}$.

(iv) If $X<T$, then the credit period is fixed at $T$ and the retailer does not pay any interest during this time interval. Alternatively, the retailer may earn revenue from product sales and interest earning.

(v) The lead time is constant. The planning horizon is infinite. The replenishment rate is instantaneous.

\subsection{2 Notation}

The following notations are used throughout the manuscript.

$\begin{array}{lll}\text { Notation } & \text { Units } & \text { Meanings } \\ c_{o} & \$ / \text { unit } & \text { Setup cost/order } \\ c_{p} & \$ / \text { unit } & \text { Purchase cost/unit } \\ \lambda & \$ / \text { unit } & \text { Discount rate } \\ p_{1} & \$ / \text { unit } & \left.\text { Price per unit of item in the non-deteriorating period (before } x_{d}\right) \\ p_{2}=(1-\lambda) p_{1} & \$ / \text { unit } & \left.\text { Price per unit of item in the deteriorating period (after } x_{d}\right) \\ A & \text { units } & \text { Highest level of initial inventory } \\ S & \text { units } & \text { Maximum shortage level } \\ c_{h} & \$ / \text { unit } & \text { Holding cost } \\ c_{b} & \$ / \text { unit } & \text { Shortage cost } \\ \theta & \text { constant } & \text { Deterioration rate, where } 0<\theta \ll 1 \\ c_{l s} & \$ / \text { unit } & \text { Lost sale cost } \\ x_{d} & \text { year } & \text { Non-deterioration time period } \\ x_{1} & \text { year } & \text { Time period when the inventory level reaches to zero } \\ X & \text { year } & \text { Cycle length } \\ U(x) & \text { units } & \text { Inventory level at time } x \\ T & \text { year } & \text { Duration of credit period } \\ I_{e} & \$ / \text { unit/year } & \text { Interest rate } \\ I_{p} & \$ / \text { unit/year } & \text { Interest paid } \\ \text { TP } & \$ / \text { year } & \text { Total profit }\end{array}$

\section{PROBlem DESCRIPTION}

At the beginning of business time, $(A+S)$ units are received by a retailer to start his business. During the time interval $0<x \leq x_{d}$, the inventory level decreases due to satisfy the customers' demand only. During the time period $x_{d}<x \leq x_{1}$, the stock decreases to meet up the joint effect of customers' demand and deterioration. Finally, at $x=x_{1}$, the inventory level reaches to zero. After that, backlogs occur in the time period $x_{1}<x \leq X$ with a rate of $[1+\mu(X-x)]^{-1}(\mu>0)$. The pictorial representation of the inventory level of the system is shown in Figure 1.

Two scenarios may arise according to the values of $x_{d}$ and $x_{1}$ as

Scenario 1. $x_{d} \leq x_{1}$.

Scenario 2. $x_{d}>x_{1}$.

Here we have investigated scenario 1 only.

Scenario 1. $x_{d} \leq x_{1}$.

In this scenario, the inventory level satisfies the following differential equations over the period $(0, X)$ :

$$
\begin{array}{ll}
\frac{\mathrm{d} U(x)}{\mathrm{d} x}=-D_{1}, & 0 \leq x \leq x_{d} \\
\frac{\mathrm{d} U(x)}{\mathrm{d} x}+\theta U(x)=-D_{2}, & x_{d}<x \leq x_{1} \\
\frac{\mathrm{d} U(x)}{\mathrm{d} x}=\frac{-D_{2}}{1+\mu(X-x)}, & x_{1}<x \leq X
\end{array}
$$




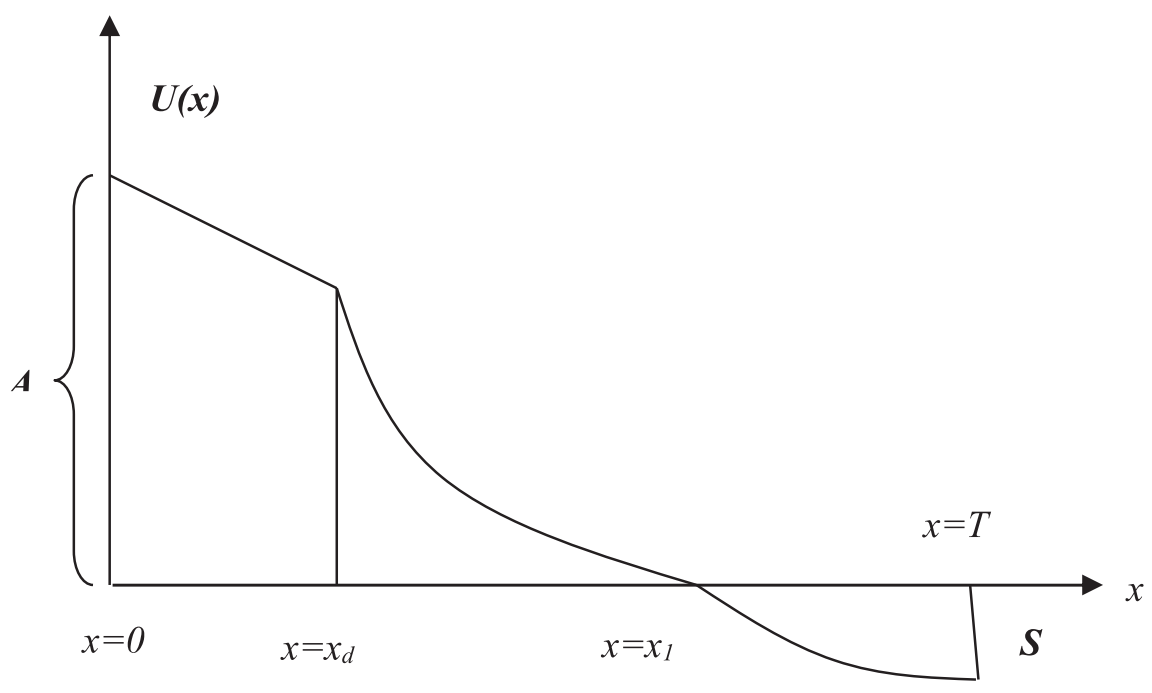

FiguRE 1. Pictorial representation of inventory situations.

using the conditions

$$
\left.\begin{array}{rl}
U(x)=A & \text { at } x=0 \\
U(x)=0 & \text { at } x=x_{1} \\
\text { and } U(x)=-S & \text { at } x=X
\end{array}\right\} \text {. }
$$

Also, $U(x)$ is also continuous at $x=x_{d}$ and $x=x_{1}$.

The solutions of differential equations (3.1)-(3.3) with the conditions (3.4) yield

$$
\begin{array}{rlrl}
U(x) & =A-D_{1} x, & 0 \leq x \leq x_{d} \\
U(x) & =\frac{D_{2}}{\theta}\left(e^{\theta\left(x_{1}-x\right)}-1\right), & & x_{d}<x \leq x_{1} \\
U(x) & =\frac{D_{2} \log |1+\mu(X-x)|}{\mu}, & & x_{1}<x \leq X .
\end{array}
$$

Again, using continuity conditions of $U(x)$ at $x=x_{d}$ and $x=x_{1}$, we obtain

$$
\begin{aligned}
A-D_{1} x_{d} & =\frac{D_{2}}{\theta}\left(e^{\theta\left(x_{1}-x\right)}-1\right) \\
S & =\frac{D_{2} \log \left|1+\mu\left(X-x_{1}\right)\right|}{\mu} .
\end{aligned}
$$

The cost function. The total cost per cycle of the inventory system consists of the following components (i) Ordering cost, (ii) Purchase cost, (iii) Inventory holding cost, (iv) Shortage cost and (v) Lost sale cost.

(a) Ordering cost: Since there is only one item and one stocking point, the ordering cost per cycle is $c_{o}$.

(b) Inventory holding cost: The inventory holding cost at any time is the product of inventory level and holding cost per unit time. Thus the total holding $C_{\text {hol }}$ is given by

$$
\begin{aligned}
C_{\mathrm{hol}} & =c_{h}\left(\int_{0}^{x_{d}} U(x) \mathrm{d} x+\int_{x_{d}}^{x_{1}} U(x) \mathrm{d} x\right) \\
& =c_{h}\left[A x_{d}-\frac{D_{1} x_{d}^{2}}{2}+D_{2}\left\{e^{\theta\left(x_{1}-x_{d}\right)}-1\right\} / \theta^{2}-D_{2}\left(x_{1}-x_{d}\right) / \theta\right] .
\end{aligned}
$$


TABLE 2. Different cases for the proposed inventory model.

\begin{tabular}{llll}
\hline \hline Cases & Time period & Sub-cases & Situations \\
\hline \multirow{2}{*}{ Case 1 } & $0<T \leq x_{d}$ & $J_{1} \geq c_{p}(A+S)$ & Full payment \\
\cline { 3 - 4 } & & $J_{1}<c_{p}(A+S)$ & Partial payment \\
\hline Case 2 & $x_{d}<T \leq x_{1}$ & $J_{2} \geq c_{p}(A+S)$ & Full payment \\
\cline { 3 - 4 } & & $J_{2}<c_{p}(A+S)$ & Partial payment \\
\hline Case 3 & $x_{1}<T$ & & - \\
\hline
\end{tabular}

(c) Purchasing cost: Since the ordering quantity is $A+S$, the total purchase cost of the entire cycle is $c_{p}(A+S)$.

(d) Shortage cost: The shortage cost at any time is the product of shortage level at that time and shortage cost per unit item. Hence the total shortage $\operatorname{cost} C_{\text {Sho }}$ of the inventory system is given by

$$
\begin{aligned}
C_{\text {Sho }} & =c_{b} \int_{x_{1}}^{X}[-U(x)] \mathrm{d} x \\
& =c_{b}\left[\left(S+\frac{D_{2}}{\mu}\right)\left(X-x_{1}\right)-D_{2}\left\{1+\mu\left(X-x_{1}\right)\right\} \log \left\{1+\mu\left(X-x_{1}\right)\right\} / \mu^{2}\right] .
\end{aligned}
$$

(e) Lost sale cost: The lost sale cost at any time is the product of unsatisfied demand and lost sale cost per unit item. Hence the total lost sale cost OCLS of the inventory system is given by

$$
\begin{aligned}
\text { OCLS } & =c_{l s} \int_{x_{1}}^{X}\left[1-\frac{1}{1+\mu(X-x)}\right] D_{2} \mathrm{~d} x \\
& =c_{l s} D_{2}\left[\left(X-x_{1}\right)-\frac{\log \left|1+\mu\left(X-x_{1}\right)\right|}{\mu}\right] .
\end{aligned}
$$

According to the trade credit policy, different cases may arise shown in Table 2.

Now we have discussed each case separately.

Case 1. $0<T \leq x_{d}$.

In this situation, retailer must pay $c_{p}(A+S)$ within the period for $x=T$. At the same time, they earn the sales revenue and interest during the entire cycle:

$$
J_{1}=D_{1} p_{1} T\left(1+\frac{1}{2} I_{e} T\right)+p_{1} S\left(1+I_{e} T\right) .
$$

According to the values of $J_{1}$ and $c_{p}(A+S)$, two possible sub-cases may arise:

Sub-case 1.1. $J_{1} \geq c_{p}(A+S)$.

Sub-case 1.2. $J_{1}<c_{p}(A+S)$.

Now we have discussed each sub-case separately.

Sub-case 1.1. $J_{1} \geq c_{p}(A+S)$.

In this situation, retailer needs to pay an amount $c_{p}(A+S)$ to the suppliers until the time period $x=T$. Thus, retailer earns interest on the rest amount $J_{1}-c_{p}(A+S)$ during the period $[T, X]$. After the time period $x=T$, retailer earns money from sales as well as from interest earned on sales amount.

Revenue earnings throughout the period $\left[T, x_{d}\right]$ is given by $p_{1} \int_{T}^{x_{d}} D_{1} \mathrm{~d} x$, while revenue earnings during the time period $\left[x_{d}, x_{1}\right]$ is given by $p_{2} \int_{x_{d}}^{x_{1}} D_{1} \mathrm{~d} x$.

The interests earned are given by $p_{1} I_{e} \int_{T}^{x_{d}} \int_{T}^{x} D_{1} \mathrm{~d} u \mathrm{~d} x$ and $p_{2} I_{e} \int_{x_{d}}^{x_{1}} \int_{x_{d}}^{x} D_{1} \mathrm{~d} u \mathrm{~d} x$.

Hence, the profit per unit is presented as follows:

$$
Z^{(1.1))}\left(x_{1} X\right)=\frac{\mathrm{TP}_{1}}{X}
$$


where $\mathrm{TP}_{1}=\langle$ rest amount after payment $\rangle+\langle$ interest accumulated on the rest amount after payment during the time period $[T, X]+\left\langle\right.$ sales revenue during the time period $\left.\left[T, x_{d}\right]\right\rangle+\langle$ sales revenue during the time period $\left.\left[x_{d}, x_{1}\right]\right\rangle+\left\langle\right.$ interest earned during the time period $\left.\left[x_{1}, X\right]\right\rangle+\langle$ interest earned during the time period $\left.\left[x_{d}, x_{1}\right]\right\rangle+\left\langle\right.$ interest earned during the time period $\left.\left[x_{1}, X\right]\right\rangle-\langle$ cost of ordering $\rangle-\langle$ carrying cost $\rangle-\langle$ cost of Shortage $\rangle-\langle$ cost of lost sale $\rangle$,

$$
\text { i.e., } \begin{aligned}
\mathrm{TP}_{1}= & \left\{J_{1}-c_{p}(A+S)\right\}\left\{1+I_{e}(X-T)\right\}+D_{1} p_{1}\left(x_{d}-T\right)\left\{1+\frac{1}{2} I_{e}\left(x_{d}-T\right)\right\} \\
& +D_{2} p_{2}\left(x_{1}-x_{d}\right)\left\{1+\frac{1}{2} I_{e}\left(x_{1}-x_{d}\right)\right\}\left\{1+I_{e}\left(X-x_{1}\right)\right\}-c_{o}-C_{\mathrm{hol}}-C_{\text {Sho }}-\text { OCLS. }
\end{aligned}
$$

Hence, in this case, we can write the corresponding optimization problem as follows:

Problem 1. Maximize $Z^{1.1}\left(x_{1}, X\right)=\frac{\mathrm{TP}_{1}}{X}$

$$
\text { subject to } 0<T \leq x_{d}<x_{1} \text {. }
$$

Sub-case 1.2. $J_{1}<c_{p}(A+S)$.

Here, two situations may arise:

Situation 1.2.1. Part payment accepted at time $x=T$.

Situation 1.2.2. Part payment not accepted at time $x=T$.

Now, we have studied each situation separately.

Situation 1.2.1. Part payment accepted at time $x=T$.

In this situation, retailer does not have sufficient money $J_{1}$ in $x=T$. It is assumed that the remaining amount $c_{p}(A+S)-J_{1}$ is to be paid on $x=B$ (where $B>T$ ). Due to this situation, retailer must pay an interest $c_{p}(A+S)-J_{1}$ throughout the time period $[T, B]$.

The amount payable at time $x=B$ is:

$$
\left\{c_{p}(A+S)-J_{1}\right\}\left\{1+I_{p}(B-T)\right\} .
$$

The money earned from the interest on the sales amount upto time $x=B$ is $\frac{1}{2} D_{1} p_{1} I_{e}(B-T)^{2}$.

Now, the total amount on the retailer's hand $=\langle$ sales amount for the entire time period $[T, B]\rangle+\langle$ interest earned $\rangle=D_{1} p_{1}(B-T)+\frac{1}{2} D_{1} p_{1} I_{e}(B-T)^{2}=D_{1} p_{1}(B-T)\left\{1+\frac{1}{2} I_{e}(B-T)\right\}$.

Therefore, at $x=B$, the payable amount $=$ available amount is on the retailer's hand

$$
\left\{c_{p}(A+S)-J_{1}\right\}\left\{1+I_{p}(B-T)\right\}=D_{1} p_{1}(B-T)\left\{1+\frac{1}{2} I_{e}(B-T)\right\} .
$$

The simplified form of (3.14) is a quadratic equation in $B$. The admissible solution of (3.14) is given by

$$
B=T+\frac{-\left[D_{1} p_{1}-I_{p}\left\{J_{1}-c_{p}(B-T)\right\}\right] \pm \sqrt{\left[D_{1} p_{1}-I_{p}\left\{J_{1}-c_{p}(A+S)\right\}\right]^{2}-2 D_{1} p_{1} I_{e}\left\{J_{1}-c_{p}(A+S)\right\}}}{D_{1} p_{1} I_{e}} .
$$

Hence the profit per unit is presented as follows:

$$
Z^{(1.2 .1)}\left(x_{1}, X\right)=\frac{\mathrm{TP}_{2}}{X}
$$

where $\mathrm{TP}_{2}=\left\langle\right.$ sales revenue during the time period $\left.\left[B, x_{d}\right]\right\rangle+\langle$ interest earned on sales revenue during the time period $\left.\left[B, x_{d}\right]\right\rangle+\left\langle\right.$ sales revenue during the time period $\left.\left[x_{d}, x_{1}\right]\right\rangle+\langle$ interest earned on sales revenue 
during the time period $\left.\left[x_{d}, x_{1}\right]\right\rangle+\left\langle\right.$ interest earned on cash in hand during the time period $\left.\left[x_{1}, X\right]\right\rangle-$ $\langle$ cost of ordering $\rangle-\langle$ carrying cost $\rangle-\langle$ cost of backlog $\rangle-\langle$ cost of lost sale $\rangle$

$$
\begin{aligned}
\text { i.e., } \mathrm{TP}_{2}= & D_{1} p_{1}\left(x_{d}-B\right)\left\{1+\frac{1}{2} I_{e}\left(x_{d}-B\right)\right\} \\
& +D_{2} p_{2}\left(x_{1}-x_{d}\right)\left\{1+\frac{1}{2} I_{e}\left(x_{1}-x_{d}\right)\right\}\left\{1+I_{e}\left(X-x_{1}\right)\right\}-c_{o}-C_{\text {hol }}-C_{\text {Sho }}-\text { OCLS. }
\end{aligned}
$$

Hence the optimization problem can be written as

Problem 2. Maximize $Z^{(1.2 .1)}\left(x_{1}, X\right)=\frac{\mathrm{TP}_{2}}{X}$

$$
\text { subject to } 0<T \leq x_{d}<x_{1}<X \text {. }
$$

Situation 1.2.2. Part payment not accepted on $x=T$.

For this case, the supplier does not accept any fraction payment on $x=T$. However, retailer does not have the available amount to pay the supplier. Let the retailer be able to pay the amount at time $x=B$. In this situation, retailer must pay the interest to the suppliers for the entire time period $[T, B]$, that is, $c_{p}(A+S)\left\{1+I_{p}(B-T)\right\}$.

Retailer earns interest by up to time $x=B$ is $J_{1}\left\{1+I_{e}(B-T)\right\}+p_{1} D_{1}(B-T)\left\{1+\frac{1}{2} I_{e}(B-T)\right\}$.

Therefore, the amount that needs to be paid is equal to the total amount available on $x=B$

$$
\text { i.e., } c_{p}(A+S)\left\{1+I_{p}(B-T)\right\}=J_{1}\left\{1+I_{e}(B-T)\right\}+p_{1} D_{1}(B-T)\left\{1+I_{e}(B-T)\right\} .
$$

From equation (3.19), we have

$$
B=T+\frac{-\left\{D_{1} p_{1}+J_{1} I_{e}-c_{p}(A+S)\right\} \pm \sqrt{\left\{D_{1} p_{1}+J_{1} I_{e}-c_{p}(A+S)\right\}^{2}-2 D_{1} p_{1} I_{e}\left\{J_{1}-c_{p}(A+S)\right\}}}{D_{1} p_{1} I_{e}} .
$$

Hence the profit per unit is

$$
Z^{(1.2 .2)}\left(x_{1}, X\right)=\frac{\mathrm{TP}_{3}}{T}
$$

where $\mathrm{TP}_{3}=\left\langle\right.$ sales revenue during the time period $\left.\left[B, x_{d}\right]\right\rangle+\langle$ interest earned on sales revenue during the time period $\left.\left[B, x_{d}\right]\right\rangle+\left\langle\right.$ selling price $\left.\left[x_{d}, x_{1}\right]\right\rangle+\langle$ interest earned on the sales revenue during the time period $\left.\left[x_{d}, x_{1}\right]\right\rangle+\left\langle\right.$ interest earned on cash in hand during the time period $\left.\left[x_{1}, X\right]\right\rangle-\langle$ cost of ordering $\rangle-\langle$ carrying cost $\rangle-\langle$ cost of shortage $\rangle\rangle-\langle$ cost of lost sale $\rangle$

$$
\begin{aligned}
\text { i.e., } \mathrm{TP}_{2}= & D_{1} p_{1}\left(x_{d}-B\right)\left\{1+\frac{1}{2} I_{e}\left(x_{d}-B\right)\right\} \\
& +D_{1} p_{2}\left(x_{1}-x_{d}\right)\left\{1+\frac{1}{2} I_{e}\left(x_{1}-x_{d}\right)\right\}\left\{1+I_{e}\left(X-x_{1}\right)\right\}-c_{o}-C_{\text {hol }}-C_{\text {Sho }}-\text { OCLS. }
\end{aligned}
$$

The optimization problem in this situation is given by

Problem 3. Maximize $Z^{(1.2 .2)}\left(x_{1}, X\right)=\frac{\mathrm{TP}_{3}}{X}$

$$
\text { subject to } 0<T \leq x_{d}<x_{1}<X \text {. }
$$

Case 2. $x_{d}<T \leq x_{1}$.

The revenue earned on $x=T$ is given by

$$
J_{2}=p_{1} D_{1} x_{d}\left(1+\frac{1}{2} I_{e} x_{d}\right)+p_{2} D_{2}\left(T-x_{d}\right)\left\{1+\frac{1}{2} I_{e}\left(T-x_{d}\right)\right\}+p_{1} S\left(1+I_{e} x_{1}\right)+p_{2} S\left\{1+\frac{1}{2} I_{e}\left(T-x_{d}\right)\right\} .
$$

Two possible sub-cases may arise according to the values of $J_{2}$ and $c_{p}(A+S)$ : 
Sub-case 2.1. $J_{2} \geq c_{p}(A+S)$.

Sub-case 2.2. $\quad J_{2}<c_{p}(A+S)$.

Now we have discussed different sub-cases.

Sub-case 2.1. $J_{2} \geq c_{p}(A+S)$.

In this situation, retailer must pay an amount $c_{p}(A+S)$ to the suppliers until the time period of $x=T$. Therefore, retailer earns interest on amount $J_{2}-c_{p}(A+S)$ during the entire time interval of $[T, X]$. After time $x=T$, retailer also earns money from sales and interest on the sales amount.

Therefore the average profit is given by:

$$
Z^{(2.1)}\left(x_{1}, X\right)=\frac{\mathrm{TP}_{4}}{X}
$$

where $\mathrm{TP}_{4}=\langle$ rest amount after payment $\rangle+\langle$ interest earned on the rest amount during the time period $[T, X]\rangle+\left\langle\right.$ sales revenue during the time period $\left.\left[T, x_{1}\right]\right\rangle+\left\langle\right.$ interest earned during the time period $\left.\left[T, x_{1}\right]\right\rangle$ $+\left\langle\right.$ interest earned during the time period $\left.\left[x_{1}, X\right]\right\rangle-\langle$ cost of ordering $\rangle-\langle$ carrying cost $\rangle-\langle$ cost of shortage $\rangle-\langle$ cost of lost sale $\rangle$

$$
\begin{aligned}
\text { i.e., } \mathrm{TP}_{4}= & \left\{J_{2}-c_{p}(A+S)\right\}\left\{1+I_{e}(X-T)\right\} \\
& +D_{2} p_{2}\left(x_{1}-T\right)\left\{1+\frac{1}{2} I_{e}\left(x_{1}-T\right)\right\}\left\{1+I_{e}\left(X-x_{1}\right)\right\}-c_{o}-C_{\text {hol }}-C_{\text {Sho }}-\text { OCLS. }
\end{aligned}
$$

Hence the optimization problem can be written as follows:

Problem 4. Maximize $Z^{(2.1)}\left(x_{1}, X\right)=\frac{\mathrm{TP}_{4}}{X}$

$$
\text { subject to } x_{d}<T \leq x_{1}<X \text {. }
$$

Sub-case 2.2. $J_{2}<c_{p}(A+S)$.

Again, two situations may arise:

Situation 2.2.1. Part payment accepted at $x=T$.

Situation 2.2.2. Part payment not accepted at $x=T$.

Now we have discussed different situations.

Situation 2.2.1. Part payment accepted at $x=T$.

In this situation, retailer cannot have sufficient money $c_{p}(A+S)-J_{2}$ paid at time $x=B(B>T)$. Due to this situation, retailer requires to pay an interest $c_{p}(A+S)-J_{2}$ for the entire time period $[T, B]$.

Now, on $x=B$, the total amount is $\left\{c_{p}(A+S)-J_{2}\right\} I_{p}(B-T)$.

Hence the total amount payable is

$$
\left\{c_{p}(A+S)-J_{2}\right\}+\left\{c_{p}(A+S)-J_{2}\right\} I_{p}(B-T)=\left\{c_{p}(A+S)-J_{2}\right\}\left\{1+I_{p}(B-T)\right\} .
$$

The interest earned at $x=T$ is $\frac{1}{2} D_{2} p_{2} I_{e}(B-T)^{2}$ given as $D_{2} p_{2}(B-T)\left\{1+\frac{1}{2} I_{e}(B-T)\right\}$.

Therefore at $x=B$, the total payable amount $=$ available amount:

$$
\text { i.e., }\left\{c_{p}(A+S)-J_{2}\right\}\left\{1+I_{p}(B-T)\right\}=D_{2}(B-T) p_{2}+\frac{1}{2} D_{2} p_{2} I_{e}(B-T)^{2} .
$$

From equation (3.27), we have

$$
B=T+\frac{-\left[D_{2} p_{2}+I_{p}\left\{J_{2}-c_{p}(A+S)\right\}\right] \pm \sqrt{\left[D_{2} p_{2}+I_{p}\left\{J_{2}-c_{p}(A+S)\right\}\right]^{2}-2 D_{2} p_{2} I_{e}\left\{J_{2}-c_{p}(A+S)\right\}}}{D_{2} p_{2} I_{e}} .
$$


Hence the profit per unit can be written as

$$
Z^{(2.2 .1)}\left(x_{1}, X\right)=\frac{\mathrm{TP}_{5}}{X}
$$

where $\mathrm{TP}_{5}=\left\langle\right.$ sales revenue during the time period $\left.\left[B, x_{1}\right]\right\rangle+\langle$ interest earned on sales revenue during the time period $\left.\left[B, x_{1}\right]\right\rangle+\left\langle\right.$ interest earned on cash in hand during the time period $\left.\left[x_{1}, X\right]\right\rangle-\langle\operatorname{cost}$ of ordering $\rangle-\langle$ carrying cost $\rangle-\langle$ cost of shortage $\rangle-\langle$ cost of lost sale $\rangle$

$$
\text { i.e., } \mathrm{TP}_{5}=D_{2} p_{2}\left(x_{1}-B\right)\left\{1+\frac{1}{2} I_{e}\left(x_{1}-B\right)\right\}\left\{1+I_{e}\left(X-x_{1}\right)\right\}-c_{o}-C_{\text {hol }}-C_{\text {Sho }}-\text { OCLS. }
$$

In this situation, the optimization problem is as follows:

Problem 5. Maximize $Z^{(2.2 .1)}\left(x_{1}, X\right)=\frac{\mathrm{TP}_{5}}{X}$

$$
\text { subject to } x_{d}<T \leq x_{1}<X \text {. }
$$

Situation 2.2.2. Part payment cannot be accepted at $x=T$.

In this situation, the supplier cannot agree to any fraction payment $x=T$. However, retailer does not have the available amount to pay to the supplier. Let the retailer be able to pay the amount at time $x=B$. In this situation, retailer needs to pay interest to the suppliers during the period $[T, B]$.

Here the net amount is $c_{p}(A+S)\left\{1+\frac{1}{2} I_{p}(B-T)\right\}$; the total amount available at time $x=B$ is $J_{2}\left\{1+I_{e}(B-T)\right\}+p_{2} D_{2}(B-T)\left\{1+\frac{1}{2} I_{e}(B-T)\right\}$.

Hence at $x=B$, the total amount payable $=$ net amount available.

$$
\text { i.e., } c_{p}(A+S)\left\{1+I_{p}(B-T)\right\}=J_{2}\left\{1+I_{e}(B-T)\right\}+p_{2} D_{2}(B-T)\left\{1+\frac{1}{2} I_{e}(B-T)\right\} .
$$

From equation (3.32), we have

$$
B=T+\frac{-\left\{D_{2} p_{2}+J_{2} I_{e}-I_{p} c_{p}(A+S)\right\} \pm \sqrt{\left\{D_{2} p_{2}+J_{2} I_{e}-I_{p} c_{p}(A+S)\right\}^{2}-2 D_{2} p_{2} I_{e}\left\{J_{2}-c_{p}(A+S)\right\}}}{D_{2} p_{2} I_{e}} .
$$

Hence the profit per unit is

$$
Z^{(2.2 .2)}\left(x_{1}, X\right)=\frac{\mathrm{TP}_{6}}{X}
$$

where $\mathrm{TP}_{6}=\left\langle\right.$ sales revenue during the time period $\left.\left[B, x_{1}\right]\right\rangle+\langle$ interest earned on sales revenue during the time period $\left.\left[B, x_{1}\right]\right\rangle+\left\langle\right.$ interest earned on cash in hand during the time period $\left.\left[x_{1}, X\right]\right\rangle-\langle\operatorname{cost}$ of ordering $\rangle$ $-\langle$ carrying cost $\rangle-\langle$ cost of shortage $\rangle-\langle$ cost of lost sale $\rangle$

$$
\text { i.e., } \mathrm{TP}_{6}=D_{2} p_{2}\left(x_{1}-B\right)\left\{1+\frac{1}{2} I_{e}\left(x_{1}-B\right)\right\}\left\{1+I_{e}\left(X-x_{1}\right)\right\}-c_{o}-C_{\mathrm{hol}}-C_{\text {Sho }}-\text { OCLS. }
$$

In this situation, the optimization problem can be presented as follows:

Problem 6. Maximize $Z^{(2.2 .2)}\left(x_{1}, X\right)=\frac{\mathrm{TP}_{6}}{X}$

$$
\text { subject to } x_{d}<T \leq x_{1}<X \text {. }
$$

Case 3. $x_{1}<T$. 
In this scenario, the total revenue is given by

$$
\begin{aligned}
J_{3}= & D_{1} p_{1} x_{d}\left\{1+\frac{1}{2} I_{e} x_{d}\right\}+p_{2} D_{2}\left(x_{1}-x_{d}\right)\left\{1+\frac{1}{2} I_{e}\left(x_{1}-x_{d}\right)\right\}\left\{1+I_{e}\left(T-x_{1}\right)\right\}+p_{1} S\left\{1+I_{e} x_{d}\right\} \\
& +p_{2} S\left\{1+I_{e} T\right\}
\end{aligned}
$$

where $J_{3}$ is always higher than $c_{p}(A+S)$. Thus on $x=T$, the total rest amount after payment is $J_{3}-c_{p}(A+S)$. The profit per unit is $Z^{(3.3)}\left(x_{1}, X\right)=\frac{\mathrm{TP}_{7}}{X}$, where $\mathrm{TP}_{7}=\langle$ available amount $[T, X]\rangle-\langle$ cost of purchase $\rangle-$ $\langle$ cost of ordering $\rangle-\langle$ carrying cost $\rangle-\langle$ cost of shortage $\rangle-\langle$ cost of lost sale $\rangle$

$$
\text { i.e., } \mathrm{TP}_{7}=J_{3}-c_{p}(A+S)-c_{o}-C_{\mathrm{hol}}-C_{\mathrm{Sho}}-\text { OCLS. }
$$

Hence the corresponding optimization problem can be written as follows:

Problem 7. Maximize $Z^{(3.3)}\left(x_{1}, X\right)=\frac{\mathrm{TP}_{7}}{X}$

$$
\text { subject to } 0<x_{d}<x_{1}<T<X \text {. }
$$

\section{Solution PRocedure}

The optimization problems in (3.13), (3.18), (3.23), (3.26), (3.29), (3.36) and (3.38) are highly nonlinear in nature. Therefore, obtaining the analytic solutions of these optimization problems is a quite formidable task. So to solve the said optimization problem, we have applied the soft computing method IOMOT developed by Karmakar et al. [18]. The details about this technique are discussed in the next section.

\subsection{Solution procedure of the interval-oriented multi-section optimization technique (IOMOT)}

Let us assume that $f(y)$ is a function to be optimized and defined on a bounded region $a_{L} \leq y \leq a_{U}$, where $y=\left(y_{1}, y_{2}, \cdots, y_{n}\right), a_{L}=\left(a_{1 L}, a_{2 L}, \cdots, a_{n L}\right)$, and $a_{U}=\left(a_{1 U}, a_{2 U}, \cdots, a_{n U}\right) . n$ is the number of variables and $a_{i L} \leq y_{i} \leq a_{i U}, \forall i=1,2, \cdots, n$. The given region is divided into sub-regions, say $G_{1}, G_{2}, \cdots, G_{d}$, to find the maximum/minimum of function $f(y)$ in the given region using the multi-section technique [23]. With the help of interval mathematics, the value of $f(y)$ is then calculated in each region in an interval form like $f\left(G_{i}\right)=\left[f_{i L}, f_{i U}\right], \forall i=1,2, \cdots, d$, where $f_{i L}$ and $f_{i U}$ are the lower and upper bounds of $f(y)$ values in the subregions $G_{i}, \forall i=1,2, \cdots, d$. The best sub-region is then selected by comparing the intervals $f\left(G_{i}\right), \forall i=1,2, \cdots, d$ of the function values with the help of interval order relations. Repeating this process on the selected sub-region, we obtain the best value of the given function in an interval form with a negligible width.

The pseudo code of the solution procedure of IOMOT is as follows:

procedure IOMOT

begin

initialize the number of decision variables $n$;

initialize the number of divisions d;

initialize the bounds of the variables;

while termination criterion not satisfied do

divide the selected region (initially it is the given region) $a_{L} \leq y \leq a_{U}$ into sub regions

$G_{1}, G_{2}, \cdots, G_{d}$ with exhaustive form;

calculate $f_{i L}$ and $f_{i U}$ for each region $G_{i}, i=1,2, \cdots, d$ by interval mathematics;

compare these intervals $\left[f_{i L}, f_{i U}\right],(i=1,2, \cdots, d)$ by interval order relations and select best region;

end while

print the values of function value and all the decision variables in interval form;

end 
TABLE 3. Computational results for $T=60 / 365$ year.

\begin{tabular}{|c|c|c|c|c|c|c|c|}
\hline $\begin{array}{l}\text { Case/ } \\
\text { sub-case }\end{array}$ & \multicolumn{2}{|c|}{ Scenario $x_{1}$ (year) } & $X$ (year) & $A$ (unit) & $S$ (unit) & $p_{2}(\$)$ & Average profit (\$) \\
\hline 1.1 & - & {$[1.5237,1.5237]$} & {$[1.7250,1.7250]$} & 269. & 30.0132 & 45.00 & {$[4435.2656,4435.2656]$} \\
\hline \multirow[t]{2}{*}{1.2} & 1.2 .1 & , 1.5214] & {$[1.6187,1.6187]$} & 268.9716 & 15.5497 & 45.00 & {$[5111.5937,5111.5942]$} \\
\hline & 1.2 .2 & {$[1.6111,1.6111]$} & {$[1.7125,1.7125]$} & 285.4793 & 16.1601 & 45.00 & {$[4975.2509,5059.5927]$} \\
\hline
\end{tabular}

Notes. - indicates no scenario. As per condition $T \leq x_{d}$, other cases 2.1, 2.2.1, 2.2.2 and 3 are infeasible.

TABLE 4. Computational results for $T=120 / 365$ year.

\begin{tabular}{|c|c|c|c|c|c|c|c|}
\hline $\begin{array}{l}\text { Case/ } \\
\text { sub-case }\end{array}$ & \multicolumn{2}{|c|}{ Scenario $x_{1}$ (year) } & $X$ (year) & $A$ (unit) & $S$ (unit) & $p_{2}(\$)$ & Average profit (\$) \\
\hline 2.1 & - & {$[1.1328,1.1328]$} & {$[1.80,1.80]$} & 198.2465 & 78.0804 & 45.00 & {$[5100.7041,5100.7045]$} \\
\hline \multirow[t]{2}{*}{2.2} & 2.2 .1 & {$[0.2750,0.2750]$} & {$[0.5218,0.5218]$} & 46.9242 & 35.7862 & 45.00 & {$[6405.9604,6405.9604]$} \\
\hline & 2.2 .2 & \multicolumn{6}{|c|}{ Not feasible } \\
\hline
\end{tabular}

Notes. - indicates no scenario. As per condition $x_{d}<T \leq x_{1}$, other cases $1.1,1.2 .1,1.2 .2$ and 3 are infeasible.

TABle 5. Computational results for $T=210 / 365$ year.

\begin{tabular}{|c|c|c|c|c|c|c|}
\hline $\begin{array}{l}\text { Case/ } \\
\text { sub-case }\end{array}$ & Scenario $x_{1}$ (year) & $X$ (year) & $A$ (unit) & $S$ (unit) & $p_{2}(\$)$ & Average profit (\$) \\
\hline 3 & {$[0.2750,0.2750]$} & {$[0.5437,0.5437]$} & 46.9242 & 38.4500 & 45.00 & {$[6580.7061,6580.7061$} \\
\hline
\end{tabular}

Notes. - indicates no scenario. As per condition $x_{1}<T$, other cases 1.1, 1.2.1, 1.2.2, 2.1, 2.2.1 and 2.2.2 are infeasible.

In the above procedure, the termination criterion is as follows:

If for all variables $w_{i}<\varepsilon, \varepsilon$ is a pre-assigned positive number (however small), where $w_{i}=a_{i U}-a_{i L}, i=$ $1,2, \cdots, n$.

\section{Computational illustration}

We have considered a numerical example of a hypothetical inventory system and solved the optimization problems of different cases, sub-cases and scenarios using IOMOT to validate and illustrate the suggested model.

Example. The values of the different parameters are given by

$$
\begin{aligned}
c_{h} & =\$ 5 / \text { unit, } c_{o}=\$ 300 / \text { unit, } a=190, b=0.4, \theta=0.05, c_{p}=\$ 20 / \text { unit, } \mu=1.6, \\
I_{e} & =\$ 0.09 / \text { year, } I_{p}=\$ 0.12 / \text { year, } p_{1}=\$ 50 / \text { unit, } c_{b}=\$ 35 / \text { unit, } c_{l s}=\$ 35 / \text { unit }, \\
\lambda & =0.1, x_{d}=0.2 \text { year. }
\end{aligned}
$$

For different values of credit period $T$, we have solved the example using the interval-oriented multi-section optimization technique (IOMOT). The corresponding computational results are displayed in Tables 3-5.

\section{Case study 1}

In this example, we have considered a paddy stock-holder who collects paddy from farmers. During stock-in period, deterioration starts at rate $\theta=6 \%$ after a certain time $x_{d}=1.2$ months from the initial stock time. The paddy stock-holder meets up the demand continuously to the rice factory. The demand increases with the 
TABle 6. Computational results for case study 1.

\begin{tabular}{llllllll}
\hline \hline $\begin{array}{l}\text { Case } \\
\text { sub-case }\end{array}$ & Scenario & $x_{1}$ (year) & $X$ (year) & $A$ (unit) & $S$ (unit) & $p_{2}(\$)$ & Average profit $(\$)$ \\
\hline 2.1 & - & {$[6.397651,6.397651]$} & {$[12.350001,12.350001]$} & 1379.600682 & 355.048741 & 45.000000 & {$[6008.680176,6008.680176]$} \\
\hline 2.2 & 2.2 .1 & {$[7.818086,7.818086]$} & {$[12.349993,12.349993]$} & 1762.795215 & 313.878596 & 45.000000 & {$[8349.174805,8349.174805]$} \\
\cline { 2 - 8 } & 2.2 .2 & \multicolumn{5}{c}{ Not feasible } \\
\hline
\end{tabular}

Notes. - indicates no scenario. As per condition $x_{d}<T \leq x_{1}$, other cases 1.1, 1.2.1, 1.2.2 and 3 are infeasible.

TABLE 7. Computational results for case study 2 .

\begin{tabular}{llllllll}
\hline \hline $\begin{array}{l}\text { Case } \\
\text { sub-case }\end{array}$ & Scenario & $x_{1}$ (year) & $X$ (year) & $A$ (unit) & $S$ (unit) & $p_{2}(\$)$ & Average profit $(\$)$ \\
\hline 1.1 & - & {$[6.126179,6.126179]$} & {$[11.800001,11.800001]$} & 1189.099559 & 346.026368 & 40.500000 & {$[319.881012,319.881042]$} \\
\hline 1.2 & 1.2 .1 & {$[9.244313,9.244313]$} & {$[12.899999,12.899999]$} & 1890.998439 & 281.722200 & 40.500000 & {$[2112.952393,2112.952393]$} \\
\cline { 2 - 8 } & 1.2 .2 & {$[9.233523,9.233523]$} & {$[12.899998,12.899998]$} & 1888.415549 & 282.136616 & 40.500000 & {$[1933.456909,1972.654663]$} \\
\hline
\end{tabular}

Notes. - indicates no scenario. As per condition $T \leq x_{d}$, other cases 2.1, 2.2.1, 2.2 .2 and 3 are infeasible.

decreasing of selling price. Here, the demand rate without selling price is $a=200$ quintal $/$ month and selling price sensitive parameter $b=0.24$. Again, paddy stock-holder gets an offer to a credit period $T=1.97$ months to a finance organization or bank. He/she earns interest at the rate $I_{e}=9 \%$ due to default of credit period. Also the paddy stock-holder paid interest at the rate $I_{p}=12 \%$ against bank loan. The purchase cost of paddy per quintal is $c_{p}=\$ 20$ and the set up cost of paddy stock-holder is $c_{0}=\$ 250$ per cycle. The paddy stock-holder pays the holding cost is $c_{h}=\$ 0.75 /$ quintal/month. Here the paddy stock-holder allows partially backlogged shortages during stock-out period and the value of backlogged parameter is $\mu=1.06$. The backlogged cost and lost sale cost of the paddy stock-holder are $c_{b}=\$ 22$ and $c_{l s}=\$ 16$ respectively. The paddy stock-holder set up the selling price as $p_{1}=\$ 50$ per quintal before deterioration and offers $\lambda=10 \%$ discount on selling price during deterioration period. Now, the paddy stock-holder wants to determine the optimal values of initial stock, stock-in period, business period and maximum back order quantity which is to be maximized the corresponding average profit (Tab. 6).

\section{Case study 2}

Here, we have considered a potato stock-holder who collects potatoes from farmers' field directly. The potato stock-holder stocks his potatoes in a store room. During stock-in period, deterioration starts after a certain time $x_{d}=3.5$ months from the initial stock time at rate $\theta=4 \%$. The potato stock-holder meets up the demand to a market. The demand increases with the decreasing of selling price. The demand without selling price is $a=200$ quintal $/$ month and selling price sensitive parameter $b=0.24$. Again, the potato stock-holder gets advantage of credit period $T=1.97$ months to the supplier and he/she earns interest at the rate $I_{e}=9 \%$ due to default of credit period. Also the potato stock-holder would pay the interest at the rate $I_{p}=12 \%$ against bank loan. The purchase cost per quintal potatoes is $c_{p}=\$ 20$ and set up cost of potatoes stock-holder is $c_{0}=\$ 250$ per cycle. The potatoes stock-holder pays the holding cost as $c_{h}=\$ 5 /$ quintal $/$ month. Here the potato stockholder allows partially backlogged shortages during stock-out period and the value of backlogged parameter is $\mu=1.08$. The backlogged cost and lost sale cost of the potato stock-holder are $c_{b}=\$ 12$ and $c_{l s}=\$ 14$ respectively. The potato stock-holder sets up the selling price as $p_{1}=\$ 50$ per quintal during non-deterioration period and offers $\lambda=10 \%$ discount on the selling price during deterioration period. Now, the potato stockholder wants to determine the optimal values of initial stock, stock-in period, business period and maximum back order quantity which is to be maximized the corresponding average profit (Tab. 7). 


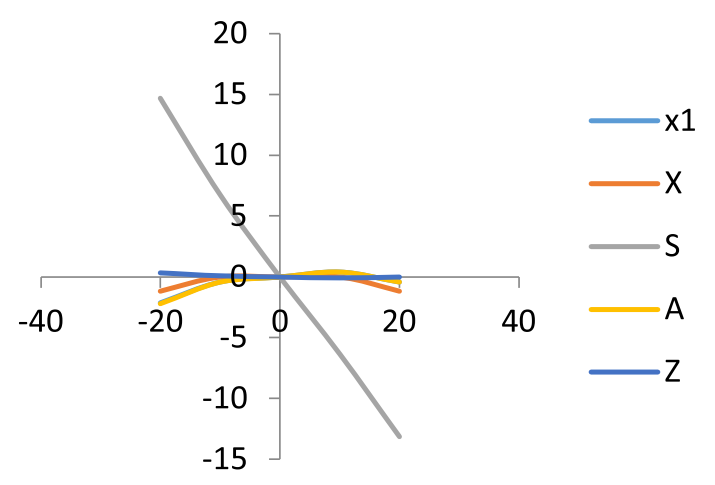

Figure 2. Post optimality study of $\delta$.

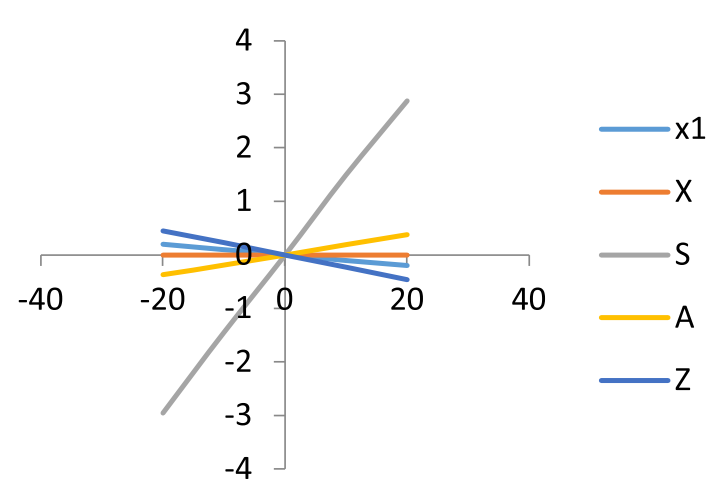

Figure 3. Post optimality study of $\theta$.

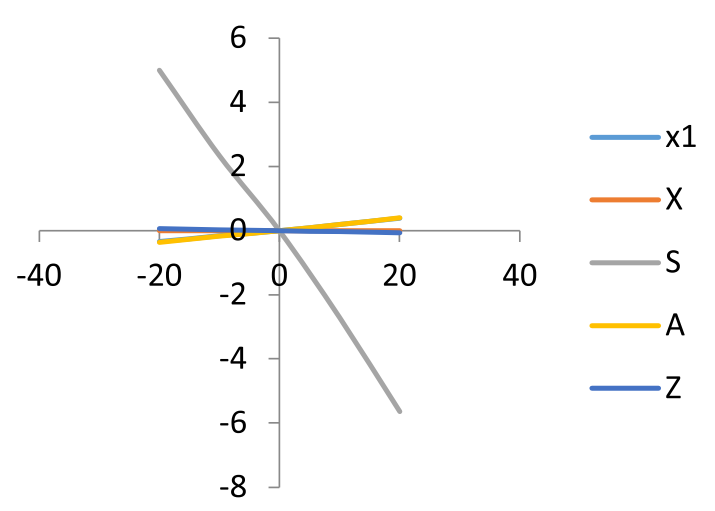

Figure 4. Post optimality study of $c_{b}$.

\section{Sensitivity ANALYSiS}

Considering first example for $T=60 / 365$, we have measured the effects of the changes by studying the values of system parameters for the time of zero inventory $\left(x_{1}\right)$, cycle length $(X)$, highest initial inventory level $(A)$, highest shortage level $(S)$ and average profit $(Z)$. For this purpose, a sensitivity analysis is performed graphically by altering one parameter ( $-20 \%$ to $20 \%)$ and keeping the other parameters as fixed ( $c f$. Figs. 2-10). 


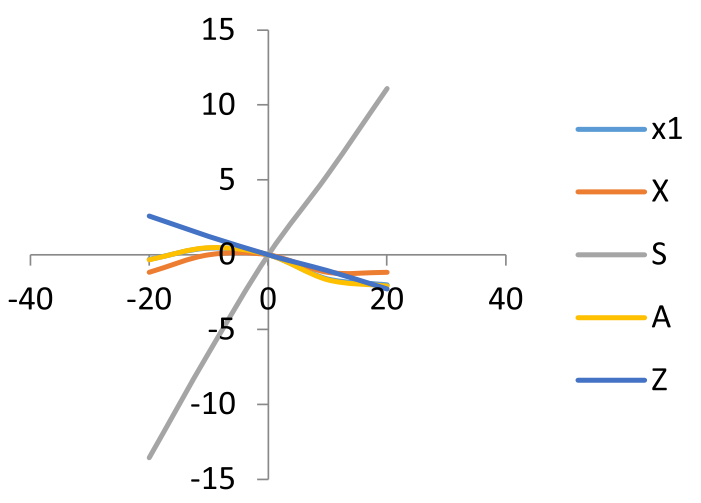

Figure 5. Post optimality study of $c_{h}$.

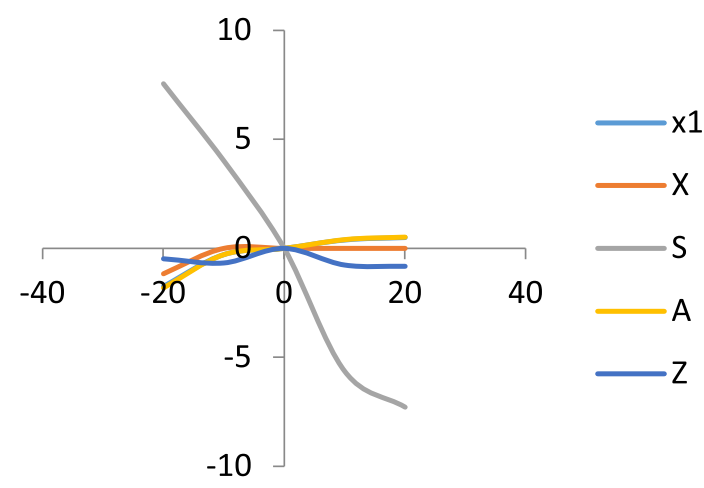

Figure 6. Post optimality study of $c_{l s}$.

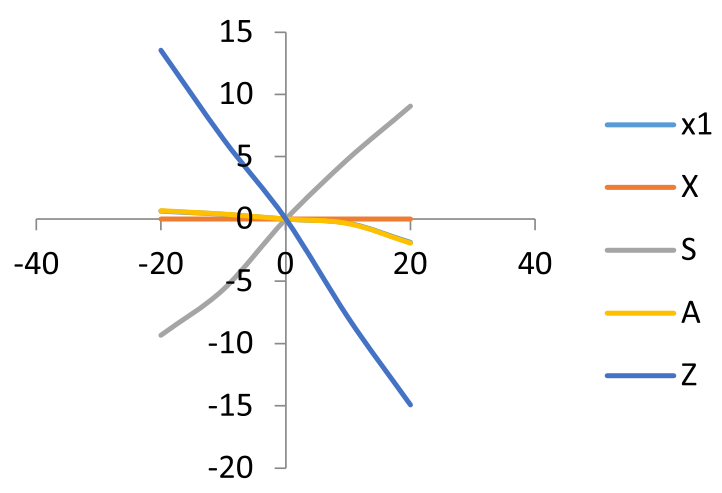

Figure 7. Post optimality study of $c_{p}$. 


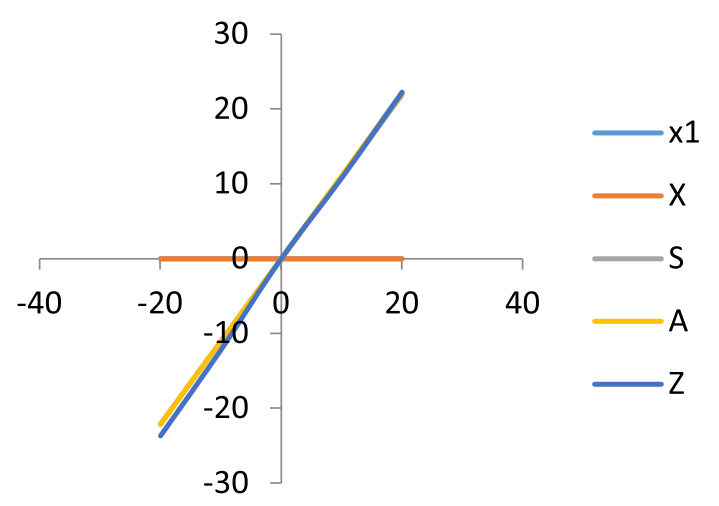

Figure 8. Post optimality study of $a$.

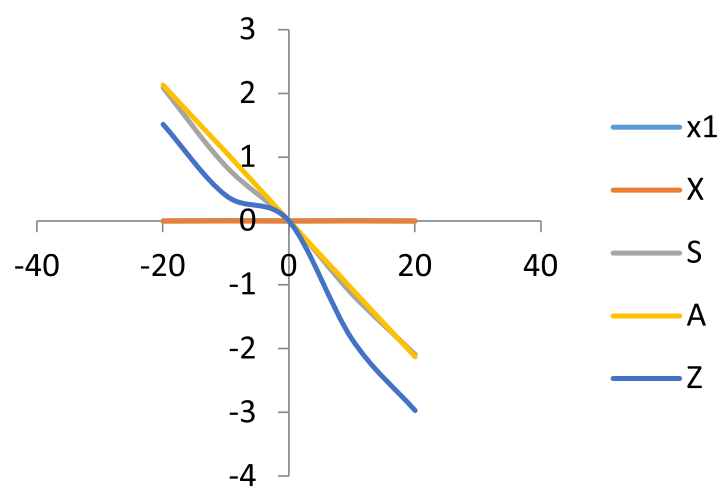

Figure 9. Post optimality study of $b$.

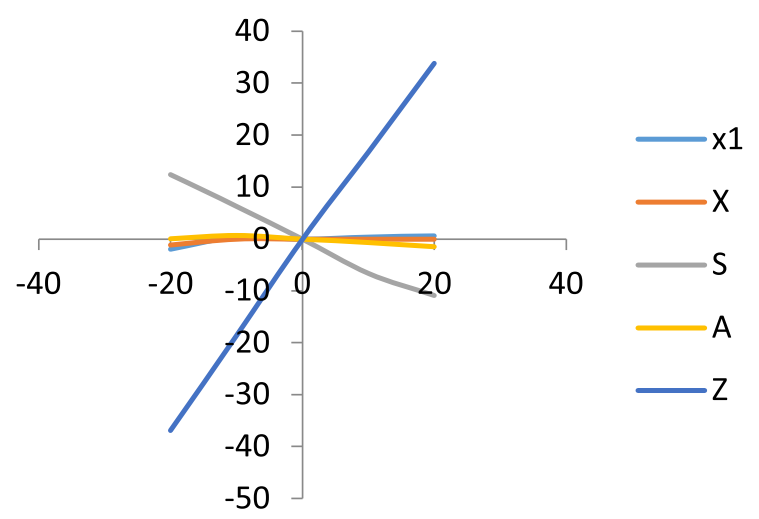

Figure 10. Post optimality study of $p_{1}$. 
From Figures 2 to 10, the following observations can be made:

(i) The total profit is highly sensible with respect to parameters $c_{p}, a, b$ and $p_{1}$. However, it is less sensitive with respect to the remaining parameters.

(ii) The highest stock is extremely sensitive with regard to parameters $a$ and $b$, which are demand-related parameters. Therefore, the change in the value of these two parameters significantly affected the demand and stock is dependent on demand. However, it is not sensitive with respect to the remaining parameters.

(iii) The maximum shortage is extremely sensible with respect to parameters $c_{l s}, c_{b}, \theta, c_{h}$ and $\mu$, but is not much sensible with respect to the other parameters.

(iv) The cycle length is strictly sensible with regard to parameter $b$, but it is not much sensible with respect to the remaining parameters.

\section{MANAGERIAL INSIGHT}

(i) Demand parameters have large impact on profit of the inventory system. Decision maker can think about demand of the product in order to increase their profit.

(ii) Purchase cost has reverse effect of profit of the inventory system. Decision maker may think about the optimal order size of the product.

(iii) Decision maker may think about initial price of the product because after certain time period they will offer price discount of the product. So, decision maker needs to take the appropriate decision about the initial price in order to avoid their loss.

\section{Concluding Remarks}

For the first time, an application of IOMOT [23] is studied in an inventory problem with variable demand and credit facility. Different cases, sub-cases and situations are investigated in the model formulation. Then the model is validated through a numerical example and two case studies. From the computational results of the example, it is observed that case 1.2.1 exhibits the best successful case among others.

Two different selling price dependent demands are considered for deterioration and non-deterioration periods of the item. In the non-deterioration period, the commodities are fresh in nature. As a result, the selling price would be high, and the demand would be less. The freshness of the commodities decreases when the deterioration effects start. A discount facility is then offered, and the selling price eventually becomes less and the demand would be high.

Finally, the proposed inventory problem can further be modified in several ways by adding some realistic features. Anyone can extend this model by taking the nonlinear holding cost and nonlinear demand. Other realistic extensions may also be used to consider the credit policy (single level, two level, or partial). Again one may extend this model by taking the inventory parameters as fuzzy or interval valued.

Acknowledgements. All authors are very much thankful to the anonymous Reviewers for their constructive comments and suggestions. The first author is very much thankful to University Grants Commission (UGC) for funding the research. The fund number is F.30-425/2018(BSR) dt. 04.01.2019. This work was supported by the National Research Foundation of Korea (NRF) grant funded by the Korea government (MSIT) (NRF-2020R1F1A1064460).

Conflict of interest. There are no conflicts of interest to declare.

Availability of data and material. There is no data available.

\section{REFERENCES}

[1] S.P. Aggarwal and C.K. Jaggi, Ordering policies of deteriorating items under permissible delay in payments. J. Oper. Res. Soc. 46 (1995) 658-662.

[2] Z.T. Balkhi and L. Benkherouf, On an inventory model for deteriorating items with stock dependent and time-varying demand rates. Comput. Oper. Res. 31 (2004) 223-240. 
[3] L. Benkherouf, A deterministic order level inventory model for deteriorating items with two storage facilities. Int. J. Prod. Econ. 48 (1997) 167-175.

[4] A.K. Bhunia and S.S. Samanta, A study of interval metric and its application in multi-objective optimization with interval objectives. Comput. Ind. Eng. 74 (2014) 169-178.

[5] A.K. Bhunia, C.K. Jaggi, A. Sharma and R. Sharma, A two ware house inventory model for deteriorating items under permissible delay in payment with partial backlogging. Appl. Math. Comput. 232 (2014) 1125-1137.

[6] A.K. Bhunia, A.A. Shaikh and L.E. Cárdenas-Barrón, A partially integrated production-inventory model with interval valued inventory costs, variable demand and flexible reliability. Appl. Soft Comput. 55 (2017) 491-502.

[7] H.J. Chang, C.H. Hung and C.Y. Dye, An inventory model for deteriorating items with linear trend demand under the condition of permissible delay in payments. Prod. Planning Control 12 (2001) 274-282.

[8] K.J. Chung and T.S. Huang, The optimal retailer's ordering policies for deteriorating items with limited storage capacity under trade-credit financing. Int. J. Prod. Econ. 106 (2007) 127-145.

[9] C.Y. Dye, L.Y. Ouyang and T.P. Hsieh, Deterministic inventory model for deteriorating items with capacity constraint and time-proportional backlogging rate, Eur. J. Oper. Res. 178 (2007) 789-807.

[10] H. Emmons, A replenishment model for radioactive nuclide generators. Manage. Sci. 14 (1968) $263-274$.

[11] P. Ghare and G. Schrader, A model for exponential decaying inventories. J. Ind. Eng. 14 (1963) $238-243$.

[12] S.K. Goyal, Economic order quantity under conditions of permissible delay in payments. J. Oper. Res. Soc. 36 (1985) $335-338$.

[13] C.W. Haley and H.C. Higgins, Inventory policy and trade-credit financing. Manage. Sci. 20 (1973) 464-471.

[14] K.L. Hou, An inventory model for deteriorating items with stock-dependent consumption rate and shortages under inflation and time discounting. Eur. J. Oper. Res. 168 (2006) 463-474.

[15] C.K. Jaggi and P. Verma, Joint optimization of price and order quantity with shortages for a two-warehouse system. Top (Spain) 16 (2008) 195-213.

[16] C. Jaggi, A. Sharma and S. Tiwari, Credit financing in economic ordering policies for non-instantaneous deteriorating items with price dependent demand under permissible delay in payments: a new approach. Int. J. Ind. Eng. Comput. 6 (2015) 481-502.

[17] C.K. Jaggi, V.S.S. Yadavalli, M. Verma and A. Sharma, An EOQ model with allowable shortage under trade credit in different scenario. Appl. Math. Comput. 252 (2015) 541-551.

[18] C.K. Jaggi, S. Tiwari and A. Shafi, Effect of deterioration on two-warehouse inventory model with imperfect quality. Comput. Ind. Eng. 88 (2015) 378-385.

[19] A.M.M. Jamal, B.R. Sarker and S. Wang, An ordering policy for deteriorating items with allowable shortages and permissible delay in payment. J. Oper. Res. Soc. 48 (1997) 826-833.

[20] Y.P. Lee and C.Y. Dye, An inventory model for deteriorating items under stock-dependent demand and controllable deterioration rate. Comput. Ind. Eng. 63 (2012) 474-482.

[21] Y. Liang and F. Zhou, A two-warehouse inventory model for deteriorating items under conditionally permissible delay in payment. Appl. Math. Model. 35 (2011) 2221-2231.

[22] J.J. Liao, K.J. Chung and K.N. Huang, A deterministic inventory model for deteriorating items with two ware houses and trade-credit in a supply chain system. Int. J. Prod. Econ. 146 (2013) 557-565.

[23] S. Karmakar, S.K. Mahato and A.K. Bhunia, Interval oriented multi-section techniques for global optimization, J. Comput. Appl. Math. 224 (2009) 476-491.

[24] A. Khanna, A. Kishore, B. Sarkar and C.K. Jaggi, Supply chain with customer-based two-level credit policies under an imperfect quality environment. Mathematics 6 (2018) 299.

[25] S. Khanra, B. Mandal and B. Sarkar, An inventory model with time dependent demand and shortages under trade-credit policy. Econ. Model. 35 (2013) 349-355.

[26] M. Kumar, A. Chauhan and R. Kumar, A deterministic inventory model for deteriorating items with price depended demand and time varying holding cost under trade-credit. Int. J. Soft Comput. Eng. 2 (2012) 99-105.

[27] V. Kumar, B. Sarkar, A.N. Sharma and M. Mittal, New product launching with pricing, free replacement, rework, and warranty policies via genetic algorithmic approach. Int. J. Comput. Intell. Syst. 12 (2019) 519-529.

[28] A. Kundu, P. Guchhait, P. Pramanik, M.K. Maiti and M. Maiti, A production inventory model with price discounted fuzzy demand using an interval compared hybrid algorithm. Swarm Evol. Comput. 34 (2017) 1-17.

[29] M.K. Maiti, A fuzzy genetic algorithm with varying population size to solve an inventory model with credit-linked promotional demand in an imprecise planning horizon. Eur. J. Oper. Res. 213 (2011) 96-106.

[30] B.A. Mandal and S. Phaujdar, An inventory model for deteriorating items and stock-dependent consumption rate. J. Oper. Res. Soc. 40 (1989) 483-488.

[31] A.H.M. Mashud, H.M. Wee, B. Sarkar and Y.H.C. Li, A sustainable inventory system with the advanced payment policy and trade-credit strategy for a two-warehouse inventory system. Kybernetes (2020). DOI: 101108/K-01-2020-0052.

[32] V.K. Mishra, L.S. Singh and R. Kumar, An inventory model for deteriorating items with time-dependent demand and timevarying holding cost under partial backlogging. J. Ind. Eng. Int. 9 (2013) 4.

[33] L. Mohsen, A.A. Taleizadeh and S.S. Sana, An inventory control problem for deteriorating items with back-ordering and financial considerations under two levels of trade-credit linked to order quantity. J. Ind. Manage. Optim. 12 (2016) 1091-1119.

[34] T.P.M. Pakkala and K.K. Achary, A deterministic inventory model for deteriorating items with two warehouses and finite replenishment rate. Eur. J. Oper. Res. 57 (1992) 71-76. 
[35] B. Pal, S.S. Sana and K. Chaudhuri, Three-stage trade-credit policy in a three layer supply chain a production inventory model. Int. J. Syst. Sci. 45 (2014) 1844-1868.

[36] S. Papachristos and K. Skouri, An inventory model with deteriorating items, quantity discount, pricing and time-dependent partial backlogging. Int. J. Prod. Econ. 83 (2003) 247-256.

[37] M. Pervin, G.C. Mahata and S.K. Roy, An inventory model with declining demand market for deteriorating items under a trade-credit policy. Int. J. Manage. Sci. Eng. Manage. 11 (2016) 243-251.

[38] A. Roy, An inventory model for deteriorating items with price dependent demand and time varying holding cost. Adv. Model. Optim. 10 (2008) 25-37.

[39] B. Sarkar, S.S. Sana and K. Chaudhuri, An inventory model with finite replenishment rate trade-credit policy and price discount offer. J. Ind. Eng. 30 (2013) 1-18.

[40] B. Sarkar, S. Saren and L.E. Cárdenas-Barrón, An inventory model with trade-credit policy and variable deterioration for fixed lifetime products. Ann. Oper. Res. 229 (2015) 677-702.

[41] B. Sarkar, W. Ahmed, S.B. Choi and M. Tayyab, Sustainable inventory management for environmental impact through partial backordering and multi-trade-credit-period. Sustainability 10 (2018) 4761.

[42] K.V.S. Sarma, A deterministic order level inventory model for deteriorating items with two storage facilities, Eur. J. Oper. Res. 29 (1987) 70-73.

[43] N.H. Shah and L.E. Cárdenas-Barrón, Retailer's decision for ordering and credit policies for deteriorating items when a supplier offers order-linked credit period or cash discount. Appl. Math. Comput. 259 (2015) 569-578.

[44] N.H. Shah, M.Y. Jani and U.B. Chaudhari, Inventory control policies for deteriorating item with preservation technology, quadratic demand, and trade-credit for a single supplier-two retailers supply chain: a centralization vs. decentralization approach. In: Handbook of Research on Promoting Business Process Improvement Through Inventory Control Techniques. IGI Global (2018) 174-193.

[45] A.A. Shaikh, L.E. Cárdenas-Barrón and S. Tiwari, A two-warehouse inventory model for non-instantaneous deteriorating items with interval-valued inventory costs and stock-dependent demand under inflationary conditions. Neural Comput. App. 31 (2019) 1931-1948.

[46] D. Shin, M. Mittal and B. Sarkar, Effects of human errors and trade-credit financing in two-echelon supply chain models. Eur. J. Ind. Eng. 12 (2018) 465-503.

[47] S. Singh, D. Khurana and S. Tayal, An Economic order quantity model for deteriorating products having stock dependent demand with trade-credit period and preservation technology. Uncertain Supply Chain Manage. 4 (2016) 29-42.

[48] H. Soni, N.H. Shah and C.K. Jaggi, Inventory model and trade-credit a review. Control Cybern. 39 (2010) 867-882.

[49] S. Tayal, S.R. Singh and R. Sharma, An integrated production inventory model for perishable products with trade-credit and investment in preservation technology. Int. J. Math. Oper. Res. 8 (2016) 137-163.

[50] J.T. Teng, J. Chen and S.K. Goyal, A comprehensive note on an inventory model under two levels of trade-credit and limited storage space derived without derivatives. Appl. Math. Model. 33 (2009) 4338-4396.

[51] S. Tiwari, W. Ahmed and B. Sarkar, Multi-item sustainable green production system under trade-credit and partial backordering. J. Cleaner Prod. 204 (2018) 82-95.

[52] R. Udayakumar and K.V. Geetha, An EOQ model for non-instantaneous deteriorating items with two levels of storage under trade-credit policy. J. Ind. Eng. Int. 14 (2018) 343-365.

[53] H.M. Wee, A deterministic lot-size inventory model for deteriorating items with shortages and a declining market. Comput. Oper. Res. 22 (1995) 345-356.

[54] J. Wu, L.Y. Ouyang and L.E. Cárdenas-Barrón, Optimal credit period and lot size for deteriorating items with a maximum life time dates under two-level trade-credit financing. Eur. J. Oper. Res. 237 (2014) 898-908. 